\title{
Corrigendum: Abiotic ligation of DNA oligomers templated by their liquid crystal ordering
}

Tommaso P. Fraccia, Gregory P. Smith, Giuliano Zanchetta, Elvezia Paraboschi, Youngwoo Yi, David M. Walba, Giorgio Dieci, Noel A. Clark \& Tommaso Bellini

Nature Communications 6:6424 doi: 10.1038/ncomms7424 (2015); Published 10 Mar 2015; Updated 17 Jun 2015

The original version of this Article contained an error in the spelling of the author Youngwoo Yi, which was incorrectly given as Yougwooo Yi. This has now been corrected in both the PDF and HTML versions of the Article. 